\title{
An LGG-derived protein promotes IgA production through upregulation of APRIL expression in intestinal epithelial cells
}

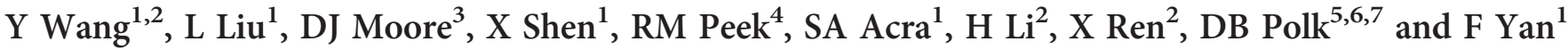

p40, a Lactobacillus rhamnosus GG (LGG)-derived protein, transactivates epidermal growth factor receptor (EGFR) in intestinal epithelial cells, leading to amelioration of intestinal injury and inflammation. To elucidate mechanisms by which p40 regulates mucosal immunity to prevent inflammation, this study aimed to determine the effects and mechanisms of p40 on regulation of a proliferation-inducing ligand (APRIL) expression in intestinal epithelial cells for promoting immunoglobulin A (IgA) production. p40 upregulated April gene expression and protein production in mouse small intestine epithelial (MSIE) cells, which were inhibited by blocking EGFR expression and kinase activity. Enteroids from Egfr $^{\mathrm{fl} / f I}$, but not Egfr ${ }^{\mathrm{fl} / \mathrm{fl}}$-Vil-Cre mice with EGFR specifically deleted in intestinal epithelial cells, exhibited increased April gene expression by $\mathrm{p} 40$ treatment. p40-conditioned media from MSIE cells increased B-cell class switching to $\lg \mathrm{A}^{+}$ cells and IgA production, which was suppressed by APRIL receptor-neutralizing antibodies. Treatment of $B$ cells with p40 did not show any effects on IgA production. p40 treatment increased April gene expression and protein production in small intestinal epithelial cells, fecal IgA levels, $\lg \mathrm{A}^{+} \mathrm{B}_{220^{+}, \operatorname{lgA}}{ }^{+} \mathrm{CD}_{19}{ }^{+}$, and $\lg \mathrm{A}^{+}$plasma cells in lamina propria of Egfr $^{\mathrm{fl} / f l}$, but not of $E g f \mathrm{fr}^{f l / f l}$-Vil-Cre, mice. Thus p40 upregulates EGFR-dependent APRIL production in intestinal epithelial cells, which may contribute to promoting IgA production.

\section{INTRODUCTION}

Immunoglobulin A (IgA), a dominant Ig isotype secreted into the intestinal lumen, serves as the first line of defense for maintaining mucosal homoeostasis by shaping homeostatic communities of commensal bacteria and protecting the host against pathogenic infections. ${ }^{1}$ It is well known that IgA is able to neutralize microbial toxins and pathogens using a highaffinity binding system and prevents commensal bacteria from breaching the mucosal surface using a low-affinity binding system, which is called immune exclusion., ${ }^{2,3}$ Remarkably, intestinal IgA achieves both immune protection and immune exclusion in a non-inflammatory manner, thereby exerting beneficial effects on the establishment of a sustainable hostmicrobial mutualism. ${ }^{4}$ Thus strategies targeting on regulation of IgA production has the potential for enhancing innate defense against commensals and pathogens.

Microbial colonization of the intestine has an important role in IgA production. Indeed, the number of IgA-secreting B cells is dramatically reduced in the intestine of germ-free animals, ${ }^{5}$ which can be counteracted by introduction of the bacterial flora. ${ }^{6}$ Commensal bacteria contribute to IgA class switching recombination in $\mathrm{B}$ cells through regulation of cytokine production in $\mathrm{CD}^{+}$T-cell-dependent and -independent manners. ${ }^{2}$ For T-cell-independent cytokine production, both intestinal dendritic cells ${ }^{7,8}$ and epithelial cells ${ }^{9,10}$ participate in this process. Studies regarding the roles of intestinal epithelial cells in IgA production reveal that antigens from commensal bacteria stimulate intestinal epithelial cells to secrete two tumor

${ }^{1}$ Division of Gastroenterology, Hepatology and Nutrition, Department of Pediatrics, Vanderbilt University Medical Center, Nashville, Tennessee, USA. ${ }^{2}$ Department of Immunology and Biotherapy Center, National Clinical Cancer Research Center, Tianjin Medical University Cancer Institute and Hospital, Tianjin, PR China. ${ }^{3}$ Division of Endocrinology, Department of Pediatrics, Vanderbilt University Medical Center, Nashville, Tennessee, USA. ${ }^{4}$ Division of Gastroenterology, Departments of Medicine and Cancer Biology, Vanderbilt University Medical Center, Nashville, Tennessee, USA. ${ }^{5}$ Department of Pediatrics, Children's Hospital Los Angeles and University of Southern California Keck School of Medicine, Los Angeles, California, USA. ${ }^{6}$ Department of Biochemistry and Molecular Biology, Children's Hospital Los Angeles and University of Southern California Keck School of Medicine, Los Angeles, California, USA and ${ }^{7}$ The Saban Research Institute, Children's Hospital Los Angeles, Los Angeles, California, USA. Correspondence: X Ren (rwziyi@yahoo.com) or DB Polk (dbpolk@chla.usc.edu) or F Yan (fang.yan@vanderbilt.edu) 
necrosis factor family members, a proliferation-inducing ligand (APRIL) and B-cell activating factor (BAFF), which direct B-cell class switching toward IgA-secreting plasma cells. ${ }^{9,11}$ These plasma cells migrate to the lamina propria under the influence of intestinal epithelial cell-derived chemokines such as C-C motif chemokine ligand 28 (CCL28). ${ }^{12}$ Eventually, IgA binds to a polymeric Ig receptor on the basolateral surface of intestinal epithelial cells and translocates to the mucosal surface to exert its functions. ${ }^{13}$

Lactobacillus rhamnosus GG (LGG), as a model commensal probiotic organism, has shown possible benefits on prevention and/or treatment of several diseases, including ulcerative colitis, ${ }^{14}$ infectious diarrhea, ${ }^{15}$ and antibiotic-associated diarrhea. ${ }^{16}$ To elucidate the mechanisms underlying the beneficial effects of LGG, our group has purified and cloned an LGGderived protein, $\mathrm{p} 40,{ }^{17}$ and demonstrated that $\mathrm{p} 40$ transactivates epidermal growth factor receptor (EGFR) in intestinal epithelial cells through activation of a disintegrin and metalloproteinase domain-containing protein-17 for HBEGF release. ${ }^{18}$ Activation of EGFR in intestinal epithelial cells by $\mathrm{p} 40$ is required for amelioration of intestinal injury and inflammation. ${ }^{19}$

To further elucidate the mechanisms underlying prevention of inflammation by $\mathrm{p} 40$, this study focused on investigating the effects of $\mathrm{p} 40$ on IgA production in the intestine. We found that p40 upregulated APRIL expression in intestinal epithelial cells in an EGFR-dependent manner, thereby increasing IgA class switching in B cells and IgA production in the intestine. Thus these results provide new information for understanding the roles of p40 in maintaining intestinal immunological homoeostasis through promoting IgA production, which may contribute to $\mathrm{p} 40$-mediated prevention of intestinal inflammation.

\section{RESULTS \\ p40 stimulates April gene expression in mouse small intestine epithelial (MSIE) cells, which promotes IgA production in B cells}

It has been shown that intestinal bacteria trigger T-cellindependent B-cell class switching in lamina propria for IgA production through expression of cytokines, such as APRIL. LGG has been reported to strengthen the immune response to viral vaccines by increasing the production of IgA. ${ }^{20,21}$ Thus we investigated the effects of $\mathrm{p} 40$-regulated intestinal epithelial cell responses on promoting IgA production.

First, we examined whether p40 stimulated MSIE cells to produce factors for promoting activation-induced cytidine deaminase (AID) expression, IgA class switching, and IgA production in B cells. Naive B cells isolated from the mouse spleen were cultured for 4 days with the treatment of $\mathrm{p} 40$ conditioned medium from MSIE cells. B cells were also treated with p40 to examine whether p40 had direct effects on B cells. $\mathrm{B}$-cell IgA class switching was examined using flow cytometric analysis. The proportion of $\operatorname{IgA}{ }^{+} \mathrm{B}_{2} 20^{+}$cells was higher in $\mathrm{B}$ cells treated with $\mathrm{p} 40$-conditioned medium than that treated with the control-conditioned medium (Figure 1a,b).
Supernatants from B-cell culture were prepared for enzyme-linked immunosorbent assay (ELISA) to detect the IgA level. The level of IgA produced by B cells treated with $\mathrm{p} 40$ conditioned medium was significantly higher than that by $\mathrm{B}$ cells treated with the control-conditioned medium (Figure 1c). Furthermore, the p40-conditioned medium increased the AID expression level in B cells (Figure 1d). However, B cells treated with p40 directly did not show the effects on AID expression, IgA class switching, and IgA production (Figure 1a-d). In addition, we found that neither $\mathrm{p} 40$-conditioned medium nor p40 direct treatment affected B-cell proliferation (Supplementary Figure S1 online).

Next we determined which factors in p40-conditioned medium mediate increased IgA production. APRIL is a known cytokine secreted by intestinal epithelial cells to trigger IgA production. ${ }^{9}$ We found that p40 upregulated April gene expression in MSIE cells in a time- and concentrationdependent manner (Figure 2a). The production of APRIL was examined by western blotting analysis of cellular lysates and ELISA analysis of APRIL release in cell culture medium. Increased cellular level of APRIL was identified in MSIE cells with p40 treatment (Figure $\mathbf{2 b}$ ). The p 40 treatment stimulated release of APRIL in MSIE cell culture medium after 6-h treatment, as compared with control medium with the same treatment time (Figure 2c).

APRIL binds two receptors on B cells, BCMA and TACI. These interactions are necessary for IgA class switching and IgA production. ${ }^{22}$ To examine whether MSIE-derived APRIL was stimulated by p40-mediated IgA induction, B cells were treated with p40-conditioned medium with APRIL receptorneutralizing antibodies, BCMA-Ig and TACI-Ig, which block APRIL binding to its receptor. MSIE cells treated with IgG were used as control. BCMA-Ig and TACI-Ig, but not control IgG, significantly reduced $\mathrm{p} 40$-conditioned medium-upregulated proportion of $\operatorname{IgA}^{+} \mathrm{B} 220^{+} \mathrm{B}$ cells and production of $\operatorname{IgA}$ (Figure 2c,d), suggesting that APRIL mediates IgA production by conditioned media from p40-treated MSIE cells.

Interestingly, control-conditioned medium from MSIE cells upregulated the proportion of $\operatorname{IgA}{ }^{+} \mathrm{B}_{22} 20^{+} \mathrm{B}$ cells (Figure $\mathbf{1 b}$ ), and this effect was not affected by BCMA-Ig and TACI-Ig (Figure 2c). These data indicate that MSIE cells secrete some factors, in addition to APRIL, in a manner independent of p40 treatment, for regulating B-cell class switching.

Taken together, these data indicate that $\mathrm{p} 40$-enhanced IgA production by $\mathrm{B}$ cells is through stimulation of APRIL secretion by intestinal epithelial cells. However, p40 does not have direct effects on B-cell activity.

\section{Activation of EGFR by p40 mediates April gene expression in MSIE cells}

EGFR is a transmembrane receptor composed of an extracellular-ligand-binding domain and an intracellular tyrosine kinase domain. Activation of EGFR leads to intracellular signaling networks and ultimately defines biological responses, such as proliferation, differentiation, migration, and survival. ${ }^{23}$ We have shown that p40 transactivates the EGFR through its 

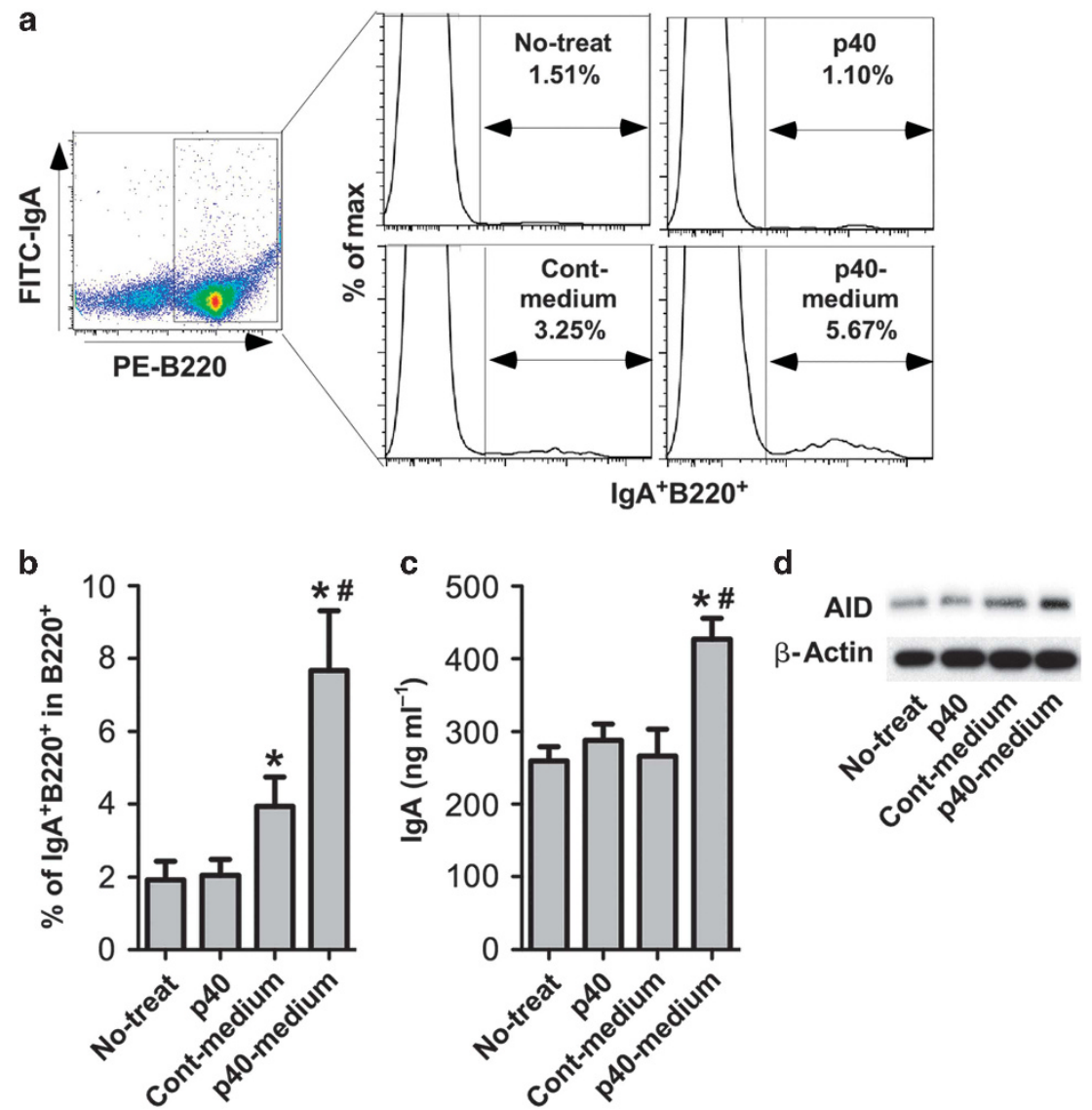

Figure 1 p40-conditioned medium from mouse small intestine epithelial (MSIE) cells, but not p40, promotes immunoglobulin A (IgA) production in B cells. MSIE cells $\left(5 \times 10^{5}\right.$ cells per well) were treated with $\mathrm{p} 40$ at $10 \mathrm{ng} \mathrm{ml}^{-1}$ in RPMI 1640 medium containing $0.5 \%$ fetal bovine serum (FBS) for $6 \mathrm{~h}$ to prepare conditioned media. B cells isolated from wild-type mouse spleen (10 6 per well) were cultured in $100 \mu$ l of RPMI containing $10 \%$ FBS and $5 \mu \mathrm{m}$ 2-mercaptoethanol (2-ME) for $6 \mathrm{~h}$ and then treated without (No-treat) and with p40 at $10 \mathrm{ng} \mathrm{ml}^{-1}$ (p40) in $100 \mu \mathrm{l}$ of B-cell culture medium, conditioned media from untreated (Cont-medium), and p40-treated (p40-medium) MSIE cells (adjust FBS to $10 \%$ and 2 -ME to $5 \mu \mathrm{M}$ ) for 4 days. ( $\mathbf{a}$ and $\mathbf{b}$ ) Characterization of IgA class switching in B cells was performed by staining B cells using fluorescein isothiocyanate (FITC)-labeled anti-IgA and phycoerythrin (PE)-labeled anti-B220 antibodies and analyzed using flow cytometry. $\mathrm{B}_{220^{+}}$cells were selected for analyzing the percentage of $\mathrm{IgA}^{+}$cells in $\mathrm{B} 220^{+}$cells. (c) Supernatants from B-cell culture were collected for analysis of the IgA level using enzyme-linked immunosorbent assay. (d) Total cellular proteins from B cells were prepared for western blotting analysis of the activation-induced cytidine deaminase protein level. $\beta$-Actin blot was used as the protein loading control. In $\mathbf{b}$ and $\mathbf{c},{ }^{\star} P<0.05$ compared with the No-treat group. ${ }^{\#} P<0.05$ compared with the Cont-medium group. Data in (b) and (c) are quantified from three independent experiments. Data in (d) are representative of three independent experiments.

downstream target, phosphoinositide 3-kinase (PI3K)/Akt, in colonic epithelial cells. ${ }^{17,19}$ We further found that 40 transactivated EGFR and Akt in MSIE cells (Figure 3a). To investigate the requirement of EGFR and Akt for p40stimulated APRIL expression, we treated MSIE cells with p40 in the presence or absence of AG1478, an EGFR kinase inhibitor, and LY294002, an inhibitor of phosphoinositide 3kinase to block Akt activation). p40- and EGF-stimulated expression of APRIL in MSIE cells (Figure $3 \mathbf{b}$ ) and release of APRIL (Supplementary Figure S2) were suppressed by AG1478 and LY294002.

To confirm these results, we transfected mouse EGFR siRNA into MSIE cells to decrease the EGFR expression. The gene expression and protein level of APRIL were significantly suppressed in MSIE cells with decreased EGFR expression, as compared with those in non-transfected and non-targeting transfected cells (Figure 3c,d).
It has been reported that nuclear factor (NF)- $\mathrm{BB}$ serves as a transcriptional factor for April gene expression ${ }^{24}$ and EGFR signaling mediates NF- $\kappa B$ activation. ${ }^{25-27}$ We examined whether p40 activated NF- $\kappa \mathrm{B}$ and whether EGFR-dependent APRIL expression by $\mathrm{p} 40$ was through activating NF- $\kappa \mathrm{B}$. We found that $\mathrm{p} 40$ activated NF- $\kappa \mathrm{B}$, detected by increased NF- $\kappa \mathrm{B}$ p65 subunit nuclear translocation in MSIE cells, which was inhibited by EGFR and Akt inhibitors (Figure 3e). These results suggest that p40 activates NF- $\mathrm{KB}$ in MSIE cells, which is mediated by EGFR activation. To examine whether NF- $\kappa B$ mediates p40-stimulated April expression, MSIE cells were co-treated with p40 and an NF- $\kappa \mathrm{B}$ inhibitor, PDTC. PDTC blocked p40-stimulated NF- $\kappa \mathrm{B}$ p65 translocation (Figure 3f) and APRIL expression (Figure 3g) in MSIE cells.

Furthermore, $E g f_{r} f l f l$-Vil-Cre mice with constitutive deletion of EGFR in the intestinal epithelial cells generated by our laboratory ${ }^{19}$ and their littermate, Egfrlffl mice, were used for 

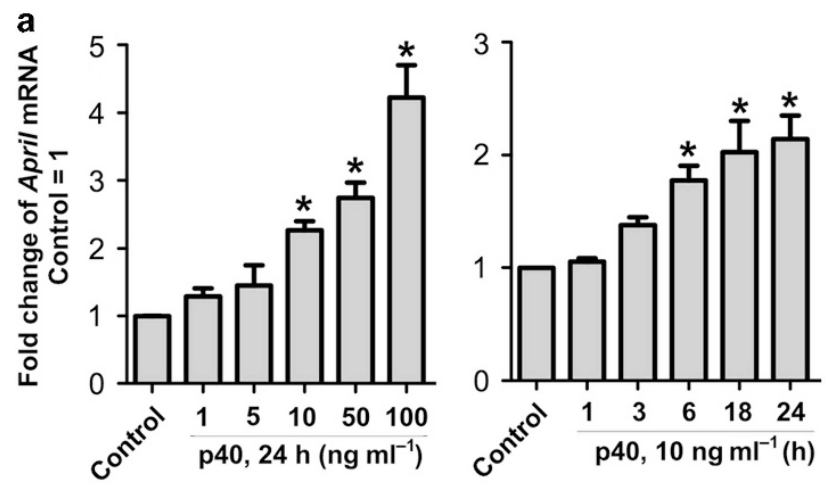

b
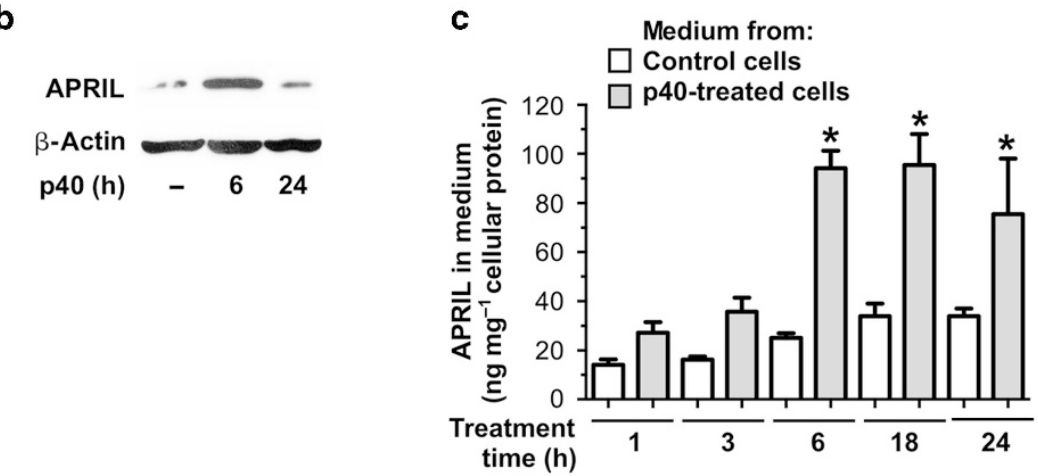

d

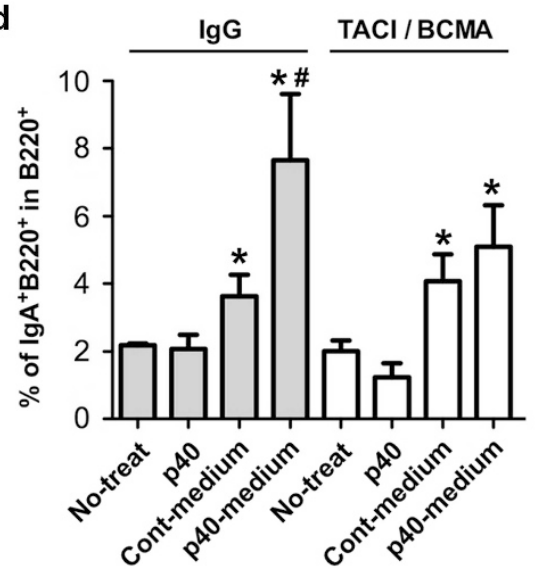

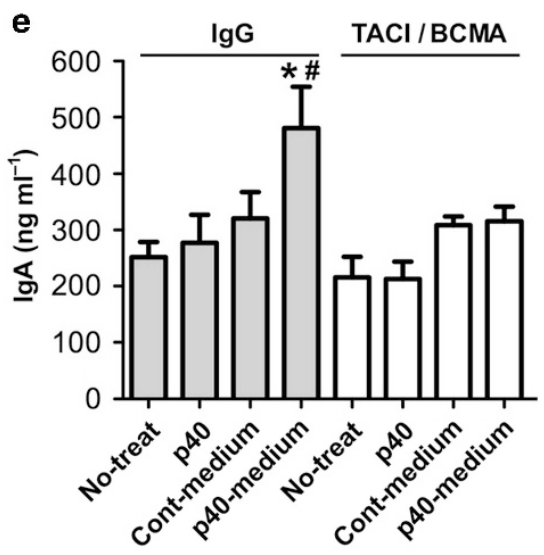

Figure 2 p40 stimulates a proliferation-inducing ligand (Apri) gene expression and protein production in mouse small intestine epithelial (MSIE) cells, which mediates upregulation of IgA production in B cells by p40-conditioned media. (a) MSIE cells were treated with p40 at the indicated concentrations for the indicated times. RNA was isolated for real-time PCR analysis of the April mRNA level. The April mRNA expression level in the control group was set as 1, and mRNA expression levels in the treated groups were compared with the control group. (b) MSIE cells were treated with $\mathrm{p} 40$ at $10 \mathrm{ng} \mathrm{ml}{ }^{-1}$ for the indicated times. Total cellular proteins were prepared for western blotting analysis of the APRIL protein level. $\beta$-Actin blot was used as the protein loading control. (c) Supernatants from MSIE cell culture with and without p40 $\left(10 \mathrm{ng} \mathrm{ml}^{-1}\right)$ treatment for the indicated times were collected for analysis of the APRIL release using enzyme-linked immunosorbent assay. (d and e) B cells were treated with p40 and p40-conditioned media for 4 days, as described in Figure 1, in the presence of neutralizing antibodies, TACl-Ig $\left(1 \mu \mathrm{g} \mathrm{ml}^{-1}\right)$ and BCMA-lg $\left(1 \mu \mathrm{g} \mathrm{ml}{ }^{-1}\right)$, to block APRIL function, and $\operatorname{lgG}\left(1 \mathrm{~g} \mathrm{ml}^{-1}\right)$ as control. IgA class switching and IgA production in B-cell culture supernatants were examined as described in Figure 1. The percentage of $\mathrm{IgA}{ }^{+} \mathrm{B}_{220}{ }^{+}$cells in $\mathrm{B}_{220}{ }^{+}$cells (d) and IgA levels in B-cell culture supernatants (e) are shown. ${ }^{*} P<0.05$ compared with the control group (a), control group with the same treatment time (c), and No-treat group (d and $\mathbf{e}),{ }^{\#} P<0.05$ compared with the Cont-medium group (d and $\left.\mathbf{e}\right)$. Data in (a) and $(\mathbf{c}-\mathbf{e})$ are quantified from at least three separate experiments. Data in (b) are representative of three independent experiments.

generating small intestinal enteroids. Consistent with our previous findings that $\mathrm{p} 40$ stimulates intestinal epithelial cell proliferation, ${ }^{17} \mathrm{p} 40$ treatment stimulated growth of enteroids from $E g f_{f}^{f l / f l}$, but not from $E g f_{r}^{f l / f l}$-Vil-Cre, mice (Figure 4a,b). In enteroids from $E g f^{f l / f l}$, April expression was significantly increased by p40 treatment, as compared with the untreated group. However, p40 failed to stimulate April expression in enteroids from $E g f_{r} r^{f l f l}$-Vil-Cre mice (Figure 4c).

These results suggest that activation of EGFR and Akt by $\mathrm{p} 40$ mediates APRIL expression in MSIE cells. Furthermore, EGFRdependent NF- $\kappa \mathrm{B}$ activation by 40 may be involved in transcriptional regulation of APRIL expression. 
a

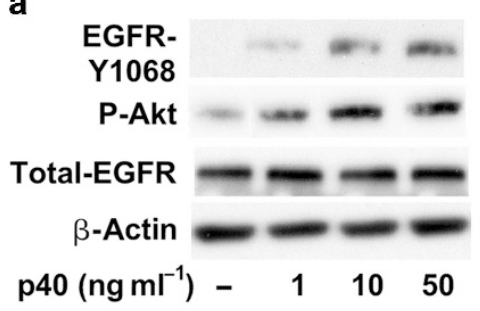

b

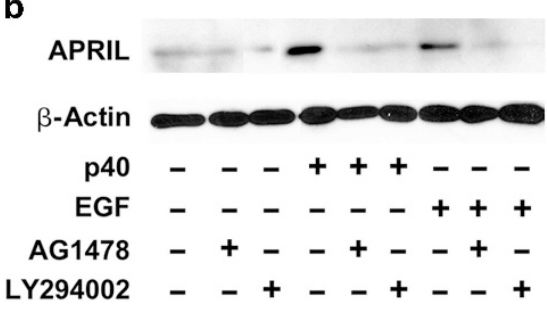

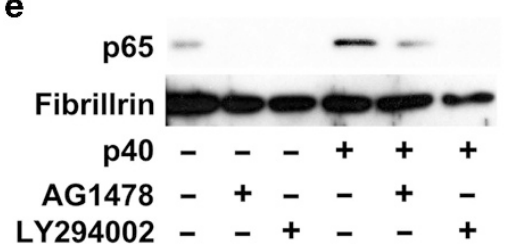

c

f

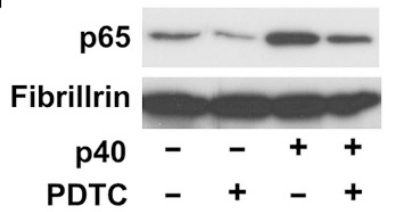

d

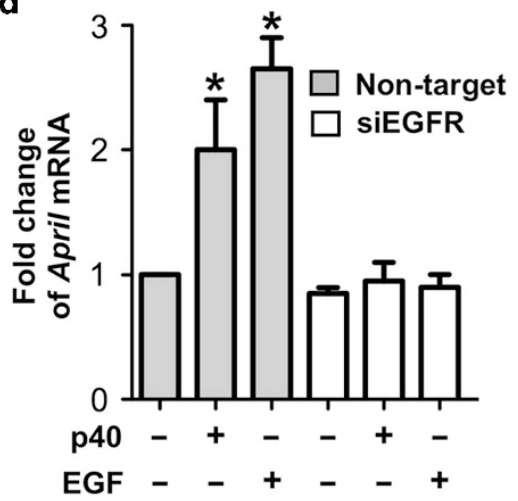

Figure 3 Activation of epidermal growth factor receptor (EGFR) mediated p40-promoted a proliferation-inducing ligand (APRIL) expression in mouse small intestine epithelial cells. (a and $\mathbf{b}$ ) Cells were treated with $\mathrm{p} 40$ at the indicated concentrations for $1 \mathrm{~h} \mathrm{(a)} \mathrm{or} \mathrm{p40} \mathrm{at} 10 \mathrm{ng} \mathrm{ml}^{-1}$ and EGF at $10 \mathrm{ng} \mathrm{ml}{ }^{-1}$ for $6 \mathrm{~h}$ in the presence and absence of AG1478 (an EGFR kinase inhibitor, $150 \mathrm{~nm}$ ) and LY294002 (a PI3K inhibitor to inhibit Akt activation, $10 \mu \mathrm{M}$ ) (b). Total cellular lysates were prepared for western blotting analysis of phosphorylated (P) and total EGFR and APRIL levels. (c and d) Cells transduced with siRNA against EGFR or non-targeting siRNA were treated with $\mathrm{p} 40\left(10 \mathrm{ng} \mathrm{ml}^{-1}\right)$ for $1 \mathrm{~h}(\mathbf{c})$ and $\mathrm{p} 40$ and EGF for $6 \mathrm{~h}$ (d). Cellular lysates were prepared for western blotting analysis and total levels of EGFR and APRIL (c). RNA was isolated for real-time PCR analysis of the AprilmRNA level. The AprilmRNA expression level in the control group with non-target transfection was set as $1(\mathbf{d})$. (e-g) Cells were treated with p40 $\left(10 \mathrm{ng} \mathrm{ml}{ }^{-1}\right.$ for $\left.1 \mathrm{~h}\right)$ in the presence and absence of AG1478 (150 nM), LY294002 (10 $\mu \mathrm{m})$, and PDTC $(50 \mu \mathrm{m})$. Nuclear proteins (e and f) and total cellular proteins (g) were prepared for western blotting analysis of nuclear factor- $\mathrm{\kappa B}$ p65 subunit nuclear translocation (e and $\mathbf{f}$ ) and APRIL expression (g). $\beta$-Actin and Fibrillirin blots were used as the protein leading control for total cellular and nuclear proteins, respectively. ${ }^{\star} P<0.05$ compared with the control group with non-target transfection $(\mathbf{d})$. Images shown in $(\mathbf{a}-\mathbf{c})$ and $(\mathbf{e}-\mathbf{g})$ are representative of three independent experiments. Data in (d) are quantified from three independent experiments.

Expression of EGFR in the intestinal epithelium mediates p40-stimulated APRIL expression, B-cell class switching, and IgA production in mice

We have demonstrated that p40 transactivation of EGFR in the intestinal epithelium has a protective role in intestinal inflammatory disorders. ${ }^{19}$ It is important to determine the role of EGFR in intestinal epithelial cells in p40-stimulated IgA production, which may contribute to protective effects of p40 on intestinal inflammation.

To investigate whether $\mathrm{p} 40$ promoted $\operatorname{IgA}^{+}$B-cell development and IgA production in vivo, wild-type mice were gavaged with $\mathrm{p} 40$ containing pectin/zein beads for 3 weeks. Pectin/zein beads without p40 were used to treat mice as controls. The fecal IgA level was significantly elevated in the mice at 2 and 3 weeks after p40 treatment as detected in our experiment. Control bead treatment did not affect the fecal IgA levels (Figure 5a). Consistent with the results, the mRNA level and protein production of APRIL in small intestinal epithelial cells were significantly increased in mice with p40 treatment (Figure 5b-d). Furthermore, p40 treatment increased the number of AID (Figure 5e,f) and IgA (Figure 5g,h) expressing cells in the lamina propria of the ileum in wild-type mice. These findings suggest that $\mathrm{p} 40$ has a role in upregulation of APRIL expression in intestinal epithelial cells for IgA production in vivo.

Our in vitro data indicate that p40 stimulates APRIL expression in an EGFR-dependent manner. Results from in vivo studies further showed that $\mathrm{p} 40$ failed to upregulate fecal IgA levels (Figure 6a), April gene expression (Figure 6b) and protein production (Figure $\mathbf{6 c}, \mathbf{d}$ ), and the number of 

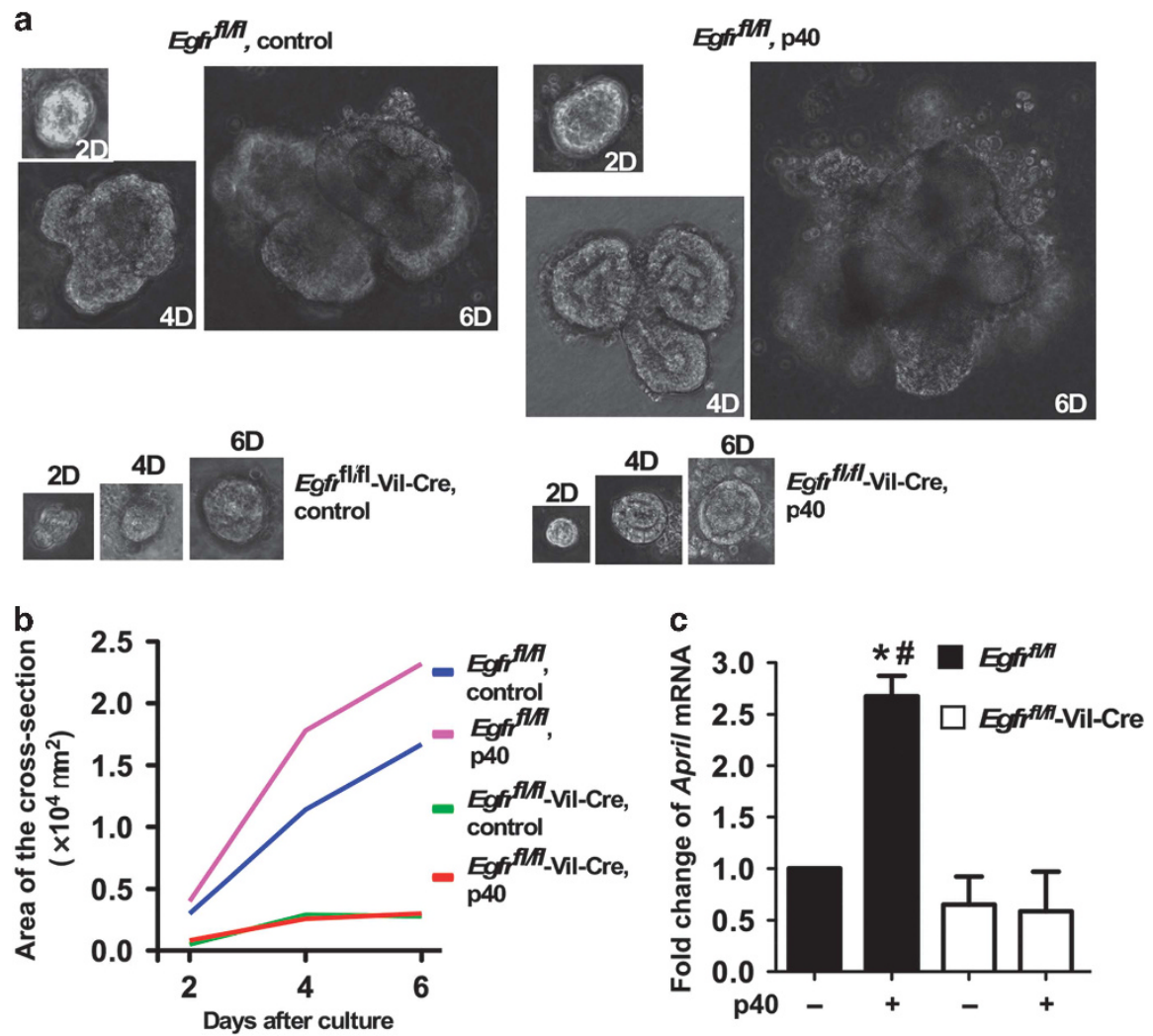

Figure 4 p40 upregulates a proliferation-inducing ligand (Apri) expression in small intestinal enteroids, which requires epidermal growth factor receptor

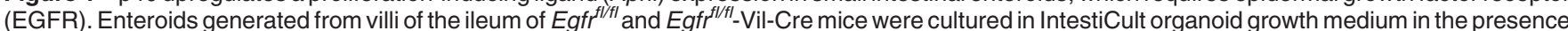
and absence of p40 (100 ng ml ${ }^{-1}$ ). (a and $\left.\mathbf{b}\right)$ Representative images and the areas of enteroids at indicated days after culture are shown. (c) RNA was isolated from enteroids cultured for 6 days for real-time PCR analysis of the April mRNA level. The April mRNA expression level in the control group from Egff ${ }^{f l / f l}$ mice was set as $1 .{ }^{*} P<0.05$ compared with the control group in Egff ${ }^{f l / f l}$ mice. ${ }^{\#} P<0.05$ compared with the p40-treated group in Egff $f^{f l / f l}$-Vil-Cre mice. Data in (b) represent the average of at least five enteroids in each condition. Data in (c) are quantified from three independent enteroid cultures.

AID-expressing cells in the lamina propria of the small intestine (Figure 6e,f) in Egff ${ }^{f l f l}$-Vil-Cre mice.

Flow cytometric analysis was performed to examine cell populations of B220 and CD19 with IgA expression in the lamina propria of the small intestine and Peyer's patches. p40 treatment did not affect the total number of $\mathrm{B}_{2} 20^{+}$and $\mathrm{CD} 19^{+}$cell populations in the lamina propria of the small intestine and Peyer's patches in $E g f_{r} f l f l$ and $E g f r l f l$-Vil-cre mice (Supplementary Figure S3). p40 treatment increased populations of $\operatorname{IgA}^{+} \mathrm{B}_{220}{ }^{+} \mathrm{B}$ and $\operatorname{IgA}{ }^{+} \mathrm{CD} 19^{+} \mathrm{B}$ cells and $\operatorname{IgA}{ }^{+}$ $\mathrm{B} 220^{-}$and $\operatorname{IgA}{ }^{+} \mathrm{CD}_{19}{ }^{-}$plasma cells in the lamina propria in $E g f r^{f l f l}$, but not in $E g f r^{f l / f l}$-Vil-cre, mice (Figure 7a,b). However, no significant effect of p40 on regulating B-cell class switching was found in the Peyper's patches in $E g f_{f} f^{l / f l}$ and $E g f f^{f l f l}$-Vil-cre mice (Supplementary Figure S4). Thus these data suggest that the effect of p40 on stimulation of B-cell class switch and IgA production occurs in the lamina propria of the small intestine, and this effect is through upregulation of EGFR-dependent APRIL expression in the intestinal epithelial cells.

\section{DISCUSSION}

One of the significant functions of the intestinal epithelial cells is their contribution for regulating the mucosal immunity in response to the intestinal microbiota. Thus we have expanded the scope of our work from understanding the mechanisms underlying p40-regulated intestinal epithelial cell survival and barrier function to elucidating the effects of p40 on IgA production in the intestinal tract. In the present study, we demonstrated that $\mathrm{p} 40$ stimulated the APRIL expression in intestinal epithelial cells and B-cell IgA class switching in the lamina propria, thereby increasing IgA production. Thus our studies provide new information for understanding the roles of probiotics in regulation of mucosal immunity and will help to guide clinical application of probiotics for host health and preventing diseases. However, although the requirement of APRIL for IgA production has been demonstrated by studies that April-deficient mice have selectively impaired IgA class switching and IgA production, ${ }^{28}$ it would be important to determine the involvement of p40-stimuated APRIL production for increasing IgA production by using APRIL-deficient mice. These experiments are ongoing in our laboratory.

This study expanded the scope of our previous finding of transactivation of EGFR by $\mathrm{p} 40$ in intestinal epithelial cells ${ }^{19,29}$ to identify the role of EGFR activation by $\mathrm{p} 40$ in regulation of APRIL expression in intestinal epithelial cells. The expression of APRIL in gene and protein levels was remarkably decreased 

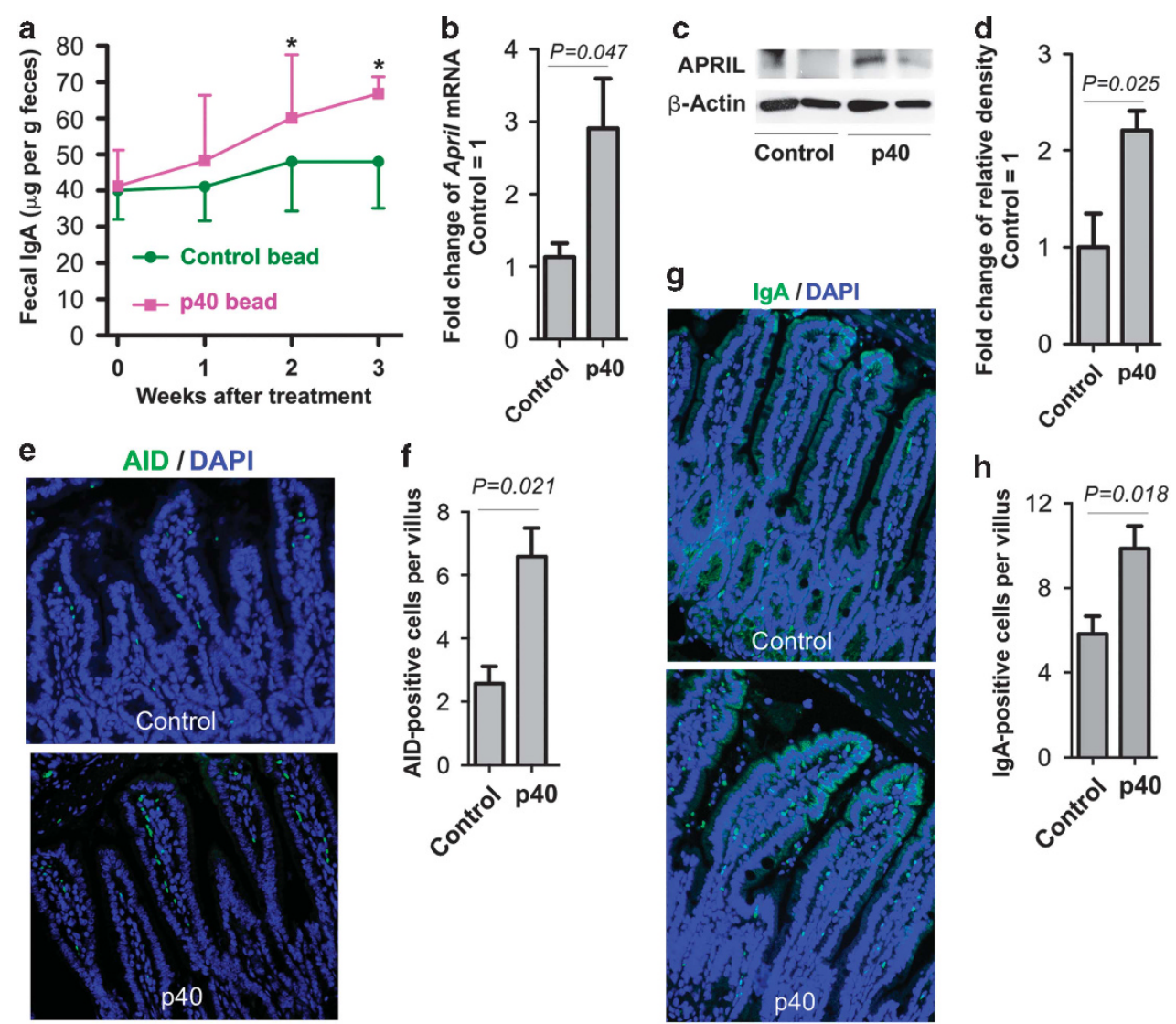

h

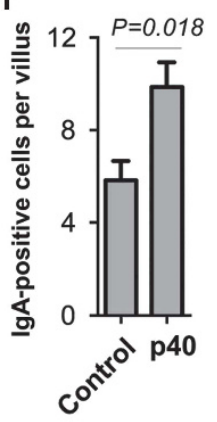

Figure 5 p40 stimulates immunoglobulin A (IgA) production in the intestine in wild-type (WT) mice. C57BL/6 WT mice were gavaged with p40 (10 $\mu$ g per day) in pectin/zein beads and beads without p40 as control. (a) Feces were collected at 1, 2, and 3 weeks after p40 treatment for detecting the IgA level using the enzyme-linked immunosorbent assay. (b-d) Small intestinal epithelial cells were isolated from mice with 3-week p40 treatment. RNA was prepared for real-time PCR analysis of the a proliferation-inducing ligand (Apri) mRNA level (b). Total cellular lysates were prepared for western blotting analysis of the APRIL protein level (c). The relative density of protein bands was determined by comparing the density of APRIL to that of $\beta$-actin bands in the same mouse sample (d). The average of the AprilmRNA level (b) and the relative density (d) in the control group was set as 1. (e-h) llea tissues were prepared for activation-induced cytidine deaminase (AID) (e) and IgA (g) immunostaining. Nuclei were stained using DAPI (4,6-diamidino-2phenylindole). The numbers of AID (f) and IgA (h) positive cells per villus are shown. ${ }^{\star} P<0.05$ compared with the control group with the same p40 treatment time in (a). $N=5$ in each group.

in intestinal epithelial cells with EGFR knockdown, resulting in suppressing of IgA production, in in vitro and in vivo experiments. Although EGFR signaling is well known to regulate several cellular responses in epithelial cells, our study first reveal the involvement of EGFR signaling regulated by the microbiota-derived factor, $\mathrm{p} 40$, in regulation of APRIL expression, thereby supporting epithelial immune functions. Furthermore, activation of NF- $\mathrm{KB}$ has been shown to be involved in April expression. ${ }^{24}$ For example, the Toll-like receptor pathway has been reported to mediate APRIL production through activation of NF- $\kappa \mathrm{B} .{ }^{10} \mathrm{We}$ found that p40 activated NF- $\mathrm{KB}$ in MSIE cells, which was mediated by EGFR and Akt activation. Furthermore, blocking NF- $\mathrm{BB}$ suppressed the effect of $\mathrm{p} 40$ on the elevation of the expression level of APRIL. All these results support the involvement of $\mathrm{NF}-\kappa \mathrm{B}$ pathway in the regulation of IgA production via EGFR activation by $\mathrm{p} 40$.

It should be noted that it has been reported that BAFF, secreted by intestinal epithelial cells, serves as another inducer of T-cell-independent IgA production. ${ }^{11}$ Interestingly, our studies found that $\mathrm{p} 40$ upregulated BAFF gene expression and protein production in MSIE cells (Supplementary Figure S5A,B) and in intestinal epithelial cells in mice (Supplementary Figure S5E,F). These effects by p40 depended on EGFR expression in intestinal epithelial cells because p40 failed to stimulate the BAFF production in MSIE cells with EGFR knockdown (Supplementary Figure S5C,D) and in Egfr $f^{l / f l}$ VilCre mice (Supplementary Figure S5E,F). Thus, in addition to APRIL, BAFF may contribute to upregulation of IgA production by $\mathrm{p} 40$. As the effect of $\mathrm{p} 40$ on upregulation of APRIL production is more potent than that on BAFF production by intestinal epithelial cells, this study was focused on investigating the regulatory role of $\mathrm{p} 40$ in APRIL production.

Intestinal epithelial cells also produce chemokines in a Toll-like receptor 4-dependent manner, including CCL20 and CCL28, to recruit B cells into lymphoid tissues and lamina propria of the intestine. ${ }^{10}$ We noticed that the proportion of $\mathrm{B} 220^{+}$and $\mathrm{CD}_{19}{ }^{+} \mathrm{B}$ cells in lamina propria and Peyer's 
a

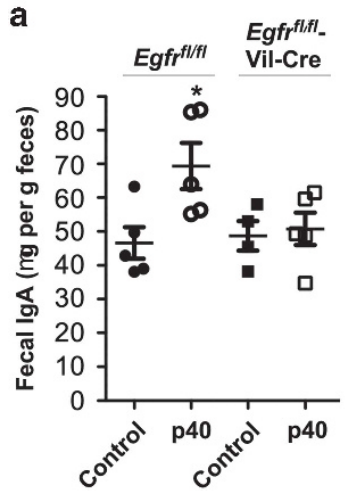

e

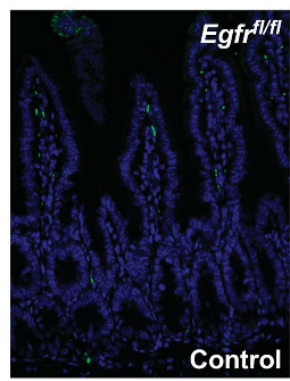

b

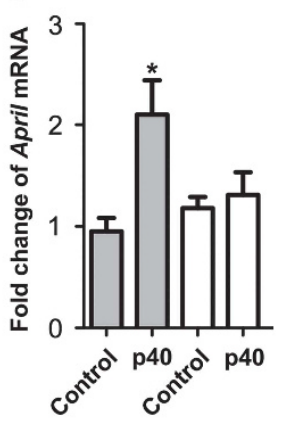

c
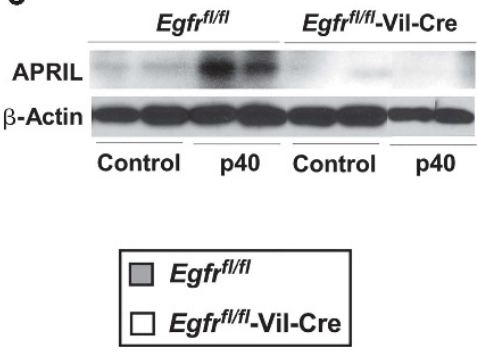

d

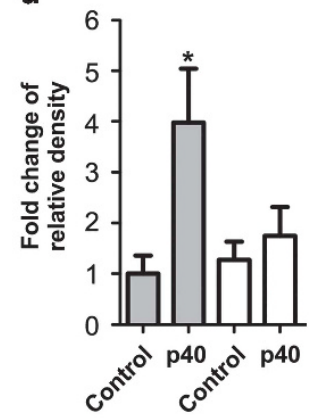

AID / DAPI

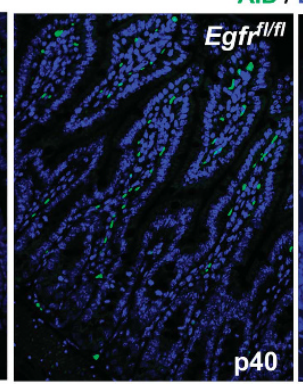

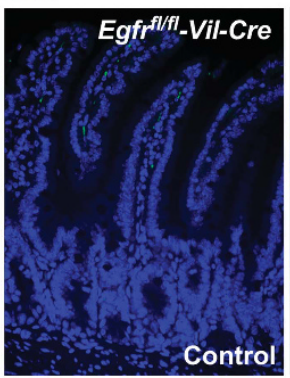
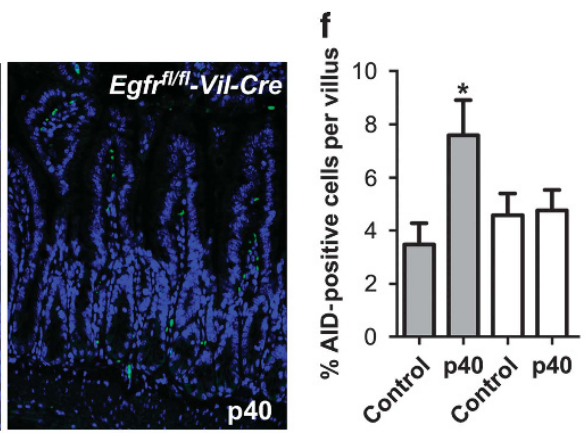

Figure 6 Epidermal growth factor receptor (EGFR) in intestinal epithelial cells mediates p40-stimulated a proliferation-inducing ligand (APRIL) and activation-induced cytidine deaminase (AID) expression and IgA production in mice. Egfr fl/fl and Egff ${ }^{f / f f l}$-Vil-Cre mice were gavaged with p40 (10 $\mu g$ per day) in pectin/zein beads or beads without p40 (control) for 3 weeks. (a) Feces were collected for detecting the level of IgA using enzyme-linked immunosorbent assay. (b) RNA was prepared from small intestinal epithelial cells for real-time PCR analysis of the April mRNA level. (c and d) Total cellular proteins were prepared from small intestinal epithelial cells for western blotting analysis of APRIL protein level. The relative density of protein bands was determined as described in Figure 5. The average of the AprilmRNA level (b) and the relative density (d) in the control group was set as 1. (e) Ilea tissues were prepared for AID immunostaining. Nuclei were stained using DAPI (4,6-diamidino-2-phenylindole). The numbers of AID-positive cells per villus are shown (f). ${ }^{*} P<0.05$ compared with the control group in Egfr ${ }^{\prime l f f}$ mice. $N=8-10$ in each group.

patches did not increase under $\mathrm{p} 40$ treatment in mice, which suggest that p40 does not influence the recruitment of B cells into the intestine and B-cell proliferation and survival. This evidence was further supported by our in vitro studies that $\mathrm{p} 40$ and $\mathrm{p} 40$-conditioned medium did not stimulate B-cell proliferation. However, the possibility that p40 treatment enhances the survival of the $\operatorname{IgA}^{+}$plasma cell population, in addition to B-cell class switching, to increase IgA production cannot be fully excluded. Thus more experiments are needed to evaluate whether p40 treatment stimulates proliferation and survival of the $\operatorname{IgA}^{+}$plasma cell population, as a mechanism for upregulation of IgA production.

Regulation of IgA responses also occurs in a region-specific manner throughout the intestine. T-cell-independent mucosal IgA production, which requires cytokines and growth factors for stimulation of B-cell activation, has been reported to occur in isolated lymphoid follicles and in the lamina propria without the formation of germinal centers. ${ }^{8,30}$ For example, studies have demonstrated that retinoic acid-related orphan receptor $\gamma \mathrm{t}+$ innate lymphoid cells produce membrane-bound lymphotoxin $\gamma$ to stimulate T-cell-independent IgA induction in the lamina propria. ${ }^{31}$ This concern is further supported by the study showing that microbial colonization influences early B-lineage development in the intestinal lamina propria. ${ }^{32}$
To provide information about the biogeography of EGFRinduced APRIL and BAFF-mediated IgA induction by $\mathrm{p} 40$, our study demonstrated the effects of p40 on B-cell class switching in the lamina propria of the small intestine. No inference on B-cell class switching in the Peyper's patches was found in mice treated with $\mathrm{p} 40$. Thus these data suggest that the effect of $\mathrm{p} 40$ on stimulation of B-cell class switch and IgA production may occur in the lamina propria.

Recent studies have shown that IgA in breast milk promoted long-term intestinal homeostasis and ameliorates colonic damage caused by dextran sodium sulfate (DSS) in adult mice, ${ }^{33}$ and bacteria coated with IgA potentially responsible for driving intestinal inflammation in patients with inflammatory bowel disease suggested the protective role of $\operatorname{IgA}$ in gut inflammation. ${ }^{34}$ We have demonstrated that 40 treatment prevents and treats DSS-induced colon epithelial cell injury and inflammation and ameliorates oxazolone and trinitrobenzene sulfonic acid-induced colitis in mice, which requires activation of EGFR in intestinal epithelial cells. ${ }^{19}$ These effects are associated with p40-regulated EGFR-dependent reduction of intestinal epithelial apoptosis and disruption of barrier function in the colonic epithelial cells in these animal models of colitis. ${ }^{19}$ We further found that p40 stimulated higher level of April expression in intestinal epithelial cells in Egfr ${ }^{f l / f l}$ mice with 
a
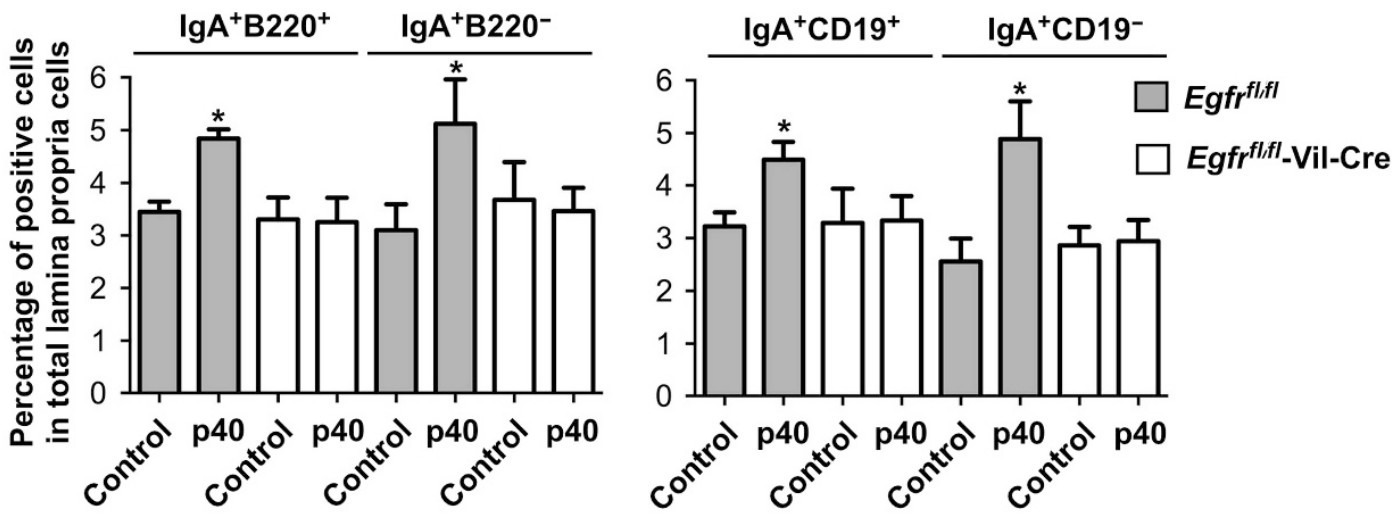

b

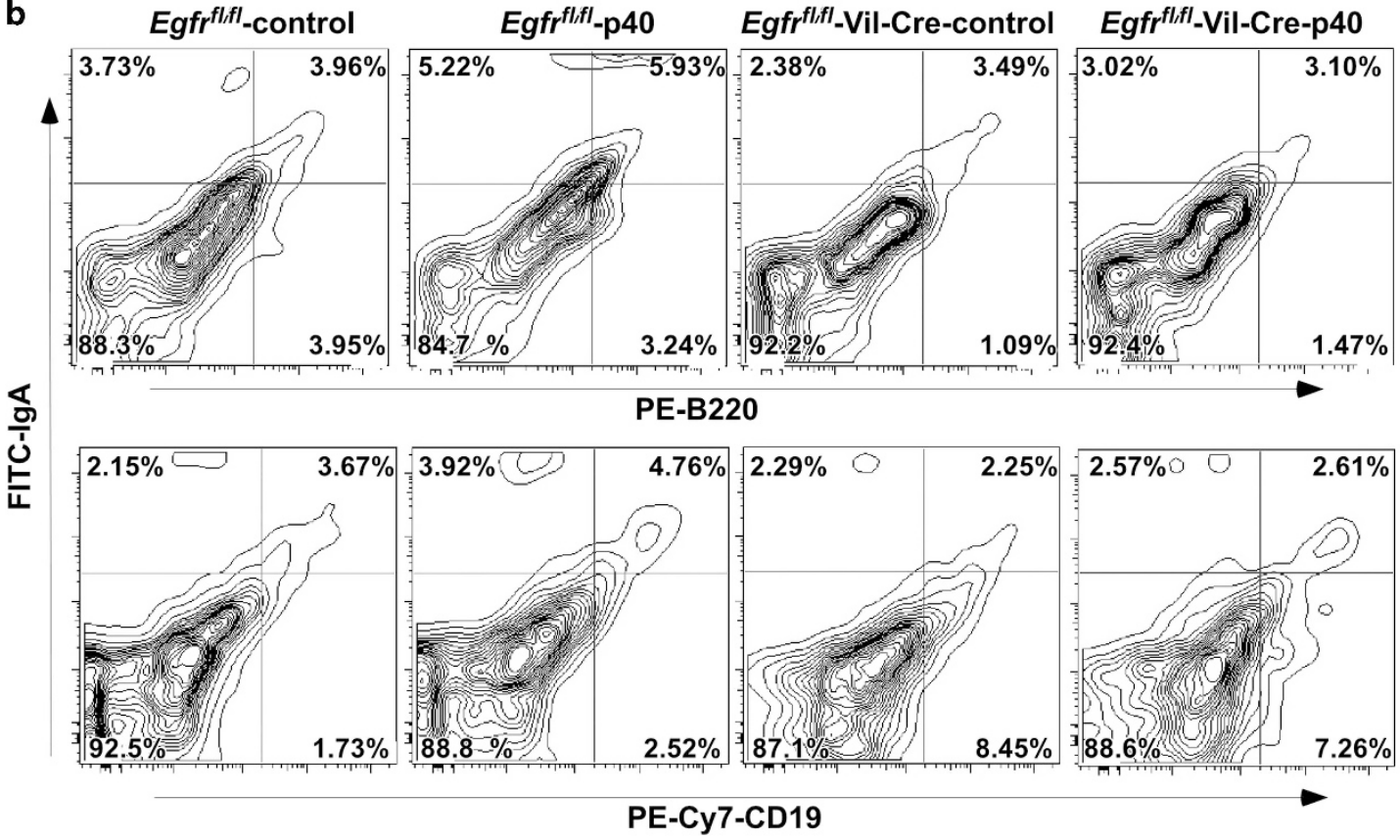

Figure 7 p40-stimulated B-cell class switching in the lamina propria requires epidermal growth factor receptor (EGFR) in mice. Egffr/flf and Egfr/flfl-VilCre mice were treated with p40 (10 $\mu \mathrm{g}$ per day) for 3 weeks as indicated in Figure 6 . Lamina propria cells were isolated from the small intestine for flow cytometric analysis of immunoglobulin A (IgA), B220, and CD19-expressing cells. (a) The percentages of the indicated positive cells in total lamina propria cells and (b) couture plots are shown. ${ }^{*} P<0.05$ compared with the control group in Egfr ${ }^{f / f t}$ mice. $N=8-10$ in each group. FITC, luorescein isothiocyanate; $\mathrm{PE}$, phycoerythrin.

DSS-induced colonic injury and colitis than that in Egfr fl/flVil-Cre mice (Supplementary Figure S6). In fact, April knockout mice have enhanced $\mathrm{T}$ helper type 2 cytokine production under non-polarizing conditions. ${ }^{35}$ Thus results from this work further emphasize the importance of promotion of IgA production and enhancement of innate defenses by $\mathrm{p} 40$ in prevention and treatment of intestinal inflammatory diseases. As it has been reported that most commensal bacteria are targeted by T-independent IgA responses, ${ }^{36}$ it is interesting to evaluate the effects of $\mathrm{p} 40$ treatment on IgA-coated intestinal bacteria, which might provide more mechanisms for understanding prevention of intestinal inflammation by $\mathrm{p} 40$.

p40 used for this study was purified from LGG culture broth. It is possible that this $\mathrm{p} 40$ preparation may be contaminated by other LGG components. Our previous works have provided evidence to confirm that the effects on regulation of intestinal epithelial cells are from p40, not from the contaminated LGG components. ${ }^{19}$ We expressed the N-terminal 1-180 aa and the C-terminal portion (aa 181-412) of p40 as recombinant peptides and found that the $\mathrm{p} 40 \mathrm{~N}$-terminal peptide was sufficient to stimulate EGFR and Akt activation in intestinal epithelial cells and prevent DSS-induced colitis. However, the C-terminal portion of p40 had no effect on EGFR and Akt activation and DSS-induced colitis. These data not only suggest that the p40 functional domain localizes in the $\mathrm{N}$-terminal 1-180 aa but indicate that the regulatory effects on intestinal epithelial cells are not exerted by contaminated bacterial components in the $\mathrm{p} 40$ preparation.

In summary, results from this study demonstrate that $\mathrm{p} 40$ stimulated activation of EGFR in intestinal epithelial cells mediates the production of APRIL, B-cell class switch in the lamina propria, and IgA production. These results reveal a 
mechanism of LGG in maintenance of intestinal mucosal homoeostasis through regulation of IgA production. Furthermore, these studies support the feasibility of applying microbiota-derived products as a strategy to promote intestinal health.

\section{METHODS}

MSIE cell culture and treatment. MSIE cells were isolated from the small intestinal epithelium of $\mathrm{H}-2 \mathrm{~Kb}$-tsA58 mice (also called Immortomouse). ${ }^{37}$ MSIE were maintained in RPMI 1640 media supplemented with $5 \%$ fetal bovine serum (FBS), $5 \mathrm{U} \mathrm{ml}^{-1}$ of murine interferon- $\gamma, 100 \mathrm{U} \mathrm{ml}^{-1}$ penicillin and streptomycin, and ITS ( $5 \mu \mathrm{g} \mathrm{ml}^{-1}$ insulin, $5 \mu \mathrm{g} \mathrm{ml}^{-1}$ transferrin, $5 \mathrm{ng} \mathrm{ml}^{-1}$ selenous acid) at $33^{\circ} \mathrm{C}$ (permissive condition) with $5 \% \mathrm{CO}_{2}$. Prior to experiments, cells were serum starved for 16-18 h in RPMI 1640 containing $0.5 \%$ FBS and $100 \mathrm{U} \mathrm{ml}^{-1}$ penicillin and streptomycin at $37^{\circ} \mathrm{C}$ (nonpermissive conditions).

p40 was isolated from LGG culture supernatant, as previously described. ${ }^{17}$ Cells were treated with p40 and human EGF (PeproTech, Rock Hill, NJ) in the presence or absence of an EGFR tyrosine kinase inhibitor, AG1478 (Calbiochem-EMD Millipore Corporation, Billerica, MA), a PI3K inhibitor, LY294002 (Calbiochem), and an NF-кB inhibitor, PDTC (Sigma-Aldrich, St Louis, MO).

Transient transfection of siRNA. MSIE cells were transiently transfected with either mouse EGFR siRNA (Dharmacon, Lafayette, CO) or nontargeting siRNA using Lipofectamine RNAiMAX reagent (Invitrogen, Waltham, MA) for $6 \mathrm{~h}$, according to the manufacturer's instructions. Cells were cultured for $24 \mathrm{~h}$ after transfection at $33^{\circ} \mathrm{C}$ and then were serum starved under the nonpermissive condition for $18 \mathrm{~h}$ before treatment. ${ }^{29}$

Isolation, culture, and treatment of B lymphocytes. B cells were isolated from the spleen of C57BL/6 mice. The spleen was mashed, suspended in magnetic cell sorting buffer, and passed through a $70-\mu \mathrm{m}$ cell strainer (BD Biosciences, San Diego, CA). B cells were purified using Mouse B lymphocyte enrichment set-DM (BD IMag, BD Biosciences) according to the manufacturer's instructions. The biotin mouse B lymphocyte enrichment cocktail containing monoclonal anti-mouse CD4, anti-mouse CD43, and anti-mouse TER-119/erythroid cells antibodies was used for the negative selection of resting conventional $\left(\mathrm{CD}^{-}\right) \mathrm{B}$ cells.

Naive B cells $\left(1 \times 10^{6}\right.$ per well $)$ were cultured in 96-well dish in $100 \mu \mathrm{l}$ of RPMI 1640 medium containing $10 \%$ FBS, $5 \mu \mathrm{M}$ 2-mercaptoethanol, and $100 \mathrm{U} \mathrm{ml}^{-1}$ penicillin and streptomycin for $6 \mathrm{~h}$. Then B cells were treated with p40 and conditioned media from MSIE cells with or without p40 treatment in the presence and absence of two goat anti-mouse neutralizing antibodies against APRIL-binding receptors on $\mathrm{B}$ cells, TACI/TNFRSF13B, which recognizes Phe5-Thr129 in TACI $\left(1 \mu \mathrm{g} \mathrm{ml}^{-1}\right)$, and BCMA/ TNFRSF17, which recognizes Met1-Thr49 in BCMA $\left(1 \mu \mathrm{g} \mathrm{ml}^{-1}\right)$ (R\&D Systems, Minneapolis, MN). Goat IgG $\left(1 \mu \mathrm{g} \mathrm{ml}^{-1}\right)$ was used as a control.

Mice and treatment. All animal experiments were performed according to protocols approved by the Institutional Animal Care and Use Committee of Vanderbilt University. Egff ${ }^{f l / f l}$ mice on a C57BL/6 background were crossed with villin-Cre mice on a C57BL/6 background to generate constitutive intestinal epithelium-specific EGFRknockout $\left(E g f r^{f l f l}\right.$-Vil-Cre) mice. ${ }^{19}$ Their littermates Egfr $r^{f l f l}$ mice were used as controls.

To deliver p40 to the small intestine and colon, $\mathrm{p} 40$-containing pectin/zein beads were prepared using the method as described in our previous publication ${ }^{19}$ with a modification. $\mathrm{p} 40$ was dissolved in pectin solution $(4 \% \mathrm{w} / \mathrm{v})$ in water and then encapsulated by zein solution $\left(0.5 \% \mathrm{w} / \mathrm{v}\right.$ in $85 \%$ ethanol) containing $\mathrm{CaCl}_{2}(0.5 \% \mathrm{w} / \mathrm{v})$. Each bead contains $5 \mu \mathrm{g}$ of p 40 with the volume of $50 \mu \mathrm{l}$. As negative controls, pectin/zein beads without $\mathrm{p} 40$ were prepared.
Four-to-six-week-old mice were gavaged with pectin/zein beads containing p40 (10 $\mu \mathrm{g}$ per day) and pectin/zein only beads, as control, for 3 weeks. Fecal samples were collected before and after p40 treatment. Small intestinal epithelial cells were isolated for RNA isolation and cellular lysate preparation. Small intestinal issues were fixed in $10 \%$ formalin for preparation of paraffin-embedded sections for immunohistochemistry.

Culture of small intestinal enteroids. The ileum tissues were cut into small fragments and washed in cold PBS buffer. Tissues were incubated

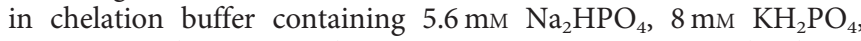
$96.2 \mathrm{~mm} \mathrm{NaCl}, 1.6 \mathrm{~mm} \mathrm{KCl}, 43.4 \mathrm{~mm}$ sucrose, $54.9 \mathrm{~mm}$ D-sorbitol, and $2 \mathrm{~mm}$ EDTA for $20 \mathrm{~min}$ at $4{ }^{\circ} \mathrm{C}$. Then villi were released by shaking tissues in cold chelation buffer containing $0.5 \mathrm{~mm}$ dithiothreitol. Supernatants were filterd through $70-\mu \mathrm{m}$ cell stainer (BIOLOGIX, Lenexa, KS) and centrifuged. Villi were washed in cold chelation buffer, mixed with Matrigel containing 25\% of IntestiCult Organoid Growth Medium (STEMCELL, Vancouver, Canada), and overlayed with this medium. Culture was performed in the absence or presence of p40 (100 $\left.\mathrm{ng} \mathrm{ml}^{-1}\right)$ in matrigel and medium.

Isolation of lymphocytes from mouse lamina propria and Peyer's patches. As described previously, ${ }^{38}$ after removing Peyer's patch, the small intestinal tissues were flushed with ice-cold calcium- and magnesium-free Hank's Balanced Salt Solution (HBSS) containing 2\% FBS, cut into small pieces, and incubated in HBSS supplemented with $1 \mathrm{~mm}$ dithiothreitol for $40 \mathrm{~min}$ with shaking at $37^{\circ} \mathrm{C}$, followed by HBSS containing $1.3 \mathrm{~mm}$ EDTA for $1 \mathrm{~h}$ at $37^{\circ} \mathrm{C}$. Tissues were further incubated in $1 \mathrm{U} \mathrm{ml}^{-1}$ collagenase D in RPMI medium for $1.5 \mathrm{~h}$ at $37^{\circ} \mathrm{C}$. Lamina propria lymphocytes were isolated on a $44 / 67 \%$ Percoll density gradient.

Lymphocytes from Peyer's patches were isolated by gently crushing the patches and incubating in Dispase and DNase solution with constant stirring at $37^{\circ} \mathrm{C}$. Lymphocytes from the supernatant were washed with RPMI.

Flow cytometric analysis. Cultured B cells and lymphocytes isolated from lamina propria and Peyer's patches of the mouse small intestine were labeled using the following antibodies: phycoerythrin (PE)anti-CD45R (B220), eBioscience, San Diego, CA), fluorescein isothiocyanate (FITC)-anti-IgA, PE-Cy7-CD19, (BD Pharmingen, San Diego, CA), PE-rat IgG2a isotype control (eBioscience), and FITC-rat IgG1 isotype control (BD Pharmingen) for $1 \mathrm{~h}$ at room temperature. Cells were analyzed using multicolor flow cytometry to determine the percentage of positive cells using a BD LSRII system (BD Biosciences).

Isolation of small intestine epithelial cells from mice. Small intestinal epithelial cells were isolated using a modified protocol. ${ }^{39}$ The small intestine was cut into small pieces and incubated with $0.5 \mathrm{~mm}$ dithiothreitol and $3 \mathrm{~mm}$ EDTA at room temperature for $1.5 \mathrm{~h}$ without shaking. After gently removing the solution, PBS was added to the small intestine. Crypts released from the small intestine by shaking the tubes. Cells were washed with PBS by centrifuging and then were solubilized in cell lysis buffer containing $1 \%$ Triton X-100, $10 \mathrm{~mm}$ Tris (pH 7.4), $1 \mathrm{~mm}$ EDTA, $1 \mathrm{~mm}$ EGTA, $150 \mathrm{~mm} \mathrm{NaCl}$, and protease and phosphatase inhibitor cocktail (Sigma-Aldrich). The protein concentration was determined using a BCA Protein Assay Kit (Thermo Fisher Scientific, Waltham, MA).

Immunohistochemistry. To unmask antigens, small intestinal sections were boiled in Antigen Unmasking Solution (Vector Laboratories, Burlingame, CA). Then sections were blocked using 10\% goat serum and stained with a rat anti-mouse IgA antibody (BD Pharmingen) and a rat anti-mouse AID antibody (eBioscience) overnight at $4{ }^{\circ} \mathrm{C}$, followed by a goat FITC-labeled anti-rat IgG antibody (Jackson ImmunoResearch, West Grove, PA) for $1 \mathrm{~h}$ at room temperature. Sections were then mounted using the Mounting Medium containing DAPI (4,6-diamidino-2-phenylindole; Vector Laboratories) for nuclear counter-staining and observed using 
fluorescence microscopy. FITC and DAPI images were taken from the same field. Positive cells in 500 vili in ileum were counted.

Real-time PCR analysis. Total RNA was isolated from MSIE cells, enteroids, and intestinal epithelial cells isolated from mice using the Qiagen RNA Isolation Kit (Thermo Fisher Scientific) and was treated with RNase-free DNase. Reverse transcription was performed using the High Capacity cDNA Reverse Transcription Kit (Thermo Fisher Scientific) for real-time PCR reactions, using the April primer mix (Mm03809849-s1), cDNA template, and Taqman Gene Expression Master Mix. Real-time PCR was performed using the Bio-Rad PCR System (Bio-Rad, Hercules, CA). The data were analyzed using the Bio-Rad CFX manager software. The relative abundance of glyceraldehyde-3-phosphate dehydrogenase mRNA was used to normalize levels of the mRNAs of interest. All cDNA samples were analyzed in triplicate.

Preparation of cellular lysates and western blotting analysis. MSIE cells and intestinal epithelial cells isolated from mice were solubilized in cell lysis buffer to prepare total cellular lysates. Nuclear fractions were prepared using NE-PER Nuclear and Cytoplasmic Extraction Reagents (Thermo Scientific, Rockford, lL) according to the manufacturer's instructions. The protein concentration was determined using a BCA Protein Assay Kit (Thermo Fisher Scientific).

Cellular and nuclear lysates were mixed with Laemmli sample buffer, and the proteins were separated by sodium dodecyl sulfatepolyacrylamide gel electrophoresis for western blotting analysis using anti-phospho-Ser473(P)-Akt (Cell Signalling, Danvers, MA), antiphospho-Tyr1068-EGFR (Cell Signalling), anti-total EGFR (Millipore, Billerica, MA), anti-APRIL (Thermo Scientific), anti-BAFF (Enzo Biochem, Farmingdale, NY), anti-AID (eBioscience), anti-p65 (Santa Cruz, Dallas, TX), anti-fibrillrin (Santa Cruz), and anti- $\beta$ actin (Sigma-Aldrich) antibodies.

ELISA analysis. For detecting IgA levels in mouse feces and B-cell culture supernatants, feces were weighted and homogenized in PBS (10\% wt:vol) using TissueLyser. Cell culture supernatants were prepared from B-cell culture. Ninety-six-well flat bottom plates (Corning, Corning, NY) were coated with anti-mouse IgA (SigmaAldrich) in PBS at $4{ }^{\circ} \mathrm{C}$ overnight. The plates were washed with wash buffer $(0.05 \%$ Tween 20 in PBS) and blocked by $1 \%$ bovine serum albumin in PBS for $1 \mathrm{~h}$ at room temperature. Then the plates were incubated with supernatants of fecal samples and culture supernatants from $\mathrm{B}$ cells for $2 \mathrm{~h}$ at room temperature, followed by a FITCconjugated anti-mouse IgA (Sigma-Aldrich) in PBS for $1 \mathrm{~h}$ at room temperature. Fluorescent intensity at $475-\mathrm{nm}$ wavelength was measured using a fluorescent plate reader. Purified mouse IgA (SigmaAldrich) was used for generating a standard concentration curve. The IgA concentration in feces was calculated as $\operatorname{IgA} \mu \mathrm{g}$ per $\mathrm{g}$ feces and in B-cell culture supernatants as IgA ng per ml culture supernatant.

For testing APRIL release in cell culture supernatants, cell culture supernatants were prepared from cultured MSIE cells and the level of APRIL was measured using a mouse APRIL ELISA Kit (Neobiolab, Woburn, MA), according to the manufacturer's instructions. The IgA concentration was calculated as IgA ng per mg of cellular proteins.

Statistical analysis. Statistical significance was determined by oneway analysis of variance for multiple comparisons and $T$-test for two sets of comparisons using Prism 6 (GraphPad Software, San Diego, CA). A $P$-value $<0.05$ was defined as statistically significant. Data are presented as mean \pm s.e.m.

SUPPLEMENTARY MATERIAL is linked to the online version of the paper at http://www.nature.com/mi

\section{ACKNOWLEDGMENTS}

This work was supported by National Institutes of Health $(\mathrm{NIH})$ grants R01DK081134 (to F.Y.) and R01DK56008 and R01DK54993 (to D.B.P.) and core services performed through Vanderbilt University Medical Center's
Digestive Disease Research Center supported by an NIH grant P30DK058404.

\section{DISCLOSURE}

The authors declared no conflict of interest.

c) 2017 Society for Mucosal Immunology

\section{REFERENCES}

1. Pabst, O. New concepts in the generation and functions of IgA. Nat. Rev. Immunol. 12, 821-832 (2012).

2. Fagarasan, S. \& Honjo, T. Intestinal IgA synthesis: regulation of front-line body defences. Nat. Rev. Immunol. 3, 63-72 (2003).

3. Macpherson, A.J., McCoy, K.D., Johansen, F.E. \& Brandtzaeg, P. The immune geography of lgA induction and function. Mucosal Immunol. 1, 11-22 (2008)

4. Macpherson, A.J. \& Harris, N.L. Interactions between commensal intestinal bacteria and the immune system. Nat. Rev. Immunol. 4, 478-485 (2004).

5. Cerutti, A. \& Rescigno, M. The biology of intestinal immunoglobulin A responses. Immunity 28, 740-750 (2008).

6. Talham, G.L., Jiang, H.Q., Bos, N.A. \& Cebra, J.J. Segmented filamentous bacteria are potent stimuli of a physiologically normal state of the murine gut mucosal immune system. Infect. Immun. 67, 1992-2000 (1999).

7. Macpherson, A.J. \& Uhr, T. Induction of protective lgA by intestinal dendritic cells carrying commensal bacteria. Science 303, 1662-1665 (2004).

8. Mora, J.R. et al. Generation of gut-homing IgA-secreting B cells by intestinal dendritic cells. Science 314, 1157-1160 (2006).

9. He, B. et al. Intestinal bacteria trigger T cell-independent immunoglobulin A(2) class switching by inducing epithelial-cell secretion of the cytokine APRIL. Immunity 26, 812-826 (2007).

10. Shang, L. et al. Toll-like receptor signaling in small intestinal epithelium promotes B-cell recruitment and IgA production in lamina propria. Gastroenterology 135, 529-538 (2008).

11. $\mathrm{Xu}, \mathrm{W}$. et al. Epithelial cells trigger frontline immunoglobulin class switching through a pathway regulated by the inhibitor SLPI. Nat. Immunol. 8, 294-303 (2007)

12. Wilson, E. \& Butcher, E.C. CCL28 controls immunoglobulin (lg)A plasma cell accumulation in the lactating mammary gland and IgA antibody transfer to the neonate. J. Exp. Med. 200, 805-809 (2004).

13. Brandtzaeg, P. \& Johansen, F.E. Confusion about the polymeric Ig receptor. Trends Immunol. 22, 545-546 (2001).

14. Zocco, M.A. et al. Efficacy of Lactobacillus GG in maintaining remission of ulcerative colitis. Aliment. Pharmacol. Ther. 23, 1567-1574 (2006).

15. Basu, S., Paul, D.K., Ganguly, S., Chatterjee, M. \& Chandra, P.K. Efficacy of high-dose Lactobacillus rhamnosus GG in controlling acute watery diarrhea in Indian children: a randomized controlled trial. J. Clin. Gastroenterol. 43, 208-213 (2009).

16. Szajewska, H., Wanke, M. \& Patro, B. Meta-analysis: the effects of Lactobacillus rhamnosus GG supplementation for the prevention of healthcare-associated diarrhoea in children. Aliment. Pharmacol. Ther. 34, 1079-1087 (2011).

17. Yan, F., Cao, H., Cover, T.L., Whitehead, R., Washington, M.K. \& Polk, D.B. Soluble proteins produced by probiotic bacteria regulate intestinal epithelial cell survival and growth. Gastroenterology 132, 562575 (2007).

18. Yan, F. et al. A Lactobacillus rhamnosus GG-derived soluble protein, p40, stimulates ligand release from intestinal epithelial cells to transactivate epidermal growth factor receptor. J. Biol. Chem. 288, 30742-30751 (2013).

19. Yan, F. et al. Colon-specific delivery of a probiotic-derived soluble protein ameliorates intestinal inflammation in mice through an EGFR-dependent mechanism. J. Clin. Invest. 121, 2242-2253 (2011).

20. Chattha, K.S. et al. Probiotics and colostrum/milk differentially affect neonatal humoral immune responses to oral rotavirus vaccine. Vaccine 31, 1916-1923 (2013).

21. de Vrese, M., Rautenberg, P., Laue, C., Koopmans, M., Herremans, T. \& Schrezenmeir, J. Probiotic bacteria stimulate virus-specific neutralizing 


\section{ARTICLES}

antibodies following a booster polio vaccination. Eur. J. Nutr. 44, 406-413 (2005).

22. Castigli, E. et al. TACl and BAFF-R mediate isotype switching in B cells. J. Exp. Med. 201, 35-39 (2005).

23. Yarden, Y. \& Sliwkowski, M.X. Untangling the ErbB signalling network. Nat. Rev. Mol. Cell Biol. 2, 127-137 (2001).

24. $\mathrm{Xu}$, J. et al. Transcription of promoter from the human APRIL gene regulated by Sp1 and NF-kB. Neoplasma 59, 341-347 (2012).

25. Biswas, D.K., Cruz, A.P., Gansberger, E. \& Pardee, A.B. Epidermal growth factor-induced nuclear factor kappa B activation: a major pathway of cell-cycle progression in estrogen-receptor negative breast cancer cells. Proc. Natl. Acad. Sci. USA 97, 8542-8547 (2000).

26. Liu, W. et al. Activation of the EGFR/Akt/NF-kappaB/cyclinD1 survival signaling pathway in human cholesteatoma epithelium. Eur. Arch. Otorhinolaryngol. 271, 265-273 (2014).

27. Sun, L. \& Carpenter, G. Epidermal growth factor activation of NF-kappaB is mediated through IkappaBalpha degradation and intracellular free calcium. Oncogene 16, 2095-2102 (1998).

28. Castigli, E. et al. Impaired IgA class switching in APRIL-deficient mice. Proc. Natl. Acad. Sci. USA 101, 3903-3908 (2004).

29. Wang, L. et al. Activation of epidermal growth factor receptor mediates mucin production stimulated by $\mathrm{p} 40$, a Lactobacillus rhamnosus GG-derived protein. J. Biol. Chem. 289, 20234-20244 (2014).

30. Macpherson, A.J., Gatto, D., Sainsbury, E., Harriman, G. R., Hengartner, H. \& Zinkernagel, R.M. A primitive Tcell-independent mechanism of intestinal mucosal IgA responses to commensal bacteria. Science 288, 2222-2226 (2000).

31. Kruglov, A.A. et al. Nonredundant function of soluble LTalpha3 produced by innate lymphoid cells in intestinal homeostasis. Science 342, 1243-1246 (2013).

32. Wesemann, D.R. Microbial colonization influences early B-lineage development in the gut lamina propria. Nature 501, 112-115 (2013).

33. Rogier, E.W. et al. Secretory antibodies in breast milk promote long-term intestinal homeostasis by regulating the gut microbiota and host gene expression. Proc. Natl. Acad. Sci. USA 111, 3074-3079 (2014).

34. Palm, N.W. et al. Immunoglobulin A coating identifies colitogenic bacteria in inflammatory bowel disease. Cell 158, 1000-1010 (2014).

35. Xiao, Y., Motomura, S. \& Podack, E.R. APRIL (TNFSF13) regulates collagen-induced arthritis, IL-17 production and Th2 response. Eur. J. Immunol. 38, 3450-3458 (2008).

36. Bunker, J.J., Flynn, T.M., Koval, J.C., Shaw, D.G., Meisel, M. \& McDonald, B.D. et al. Innate and adaptive humoral responses coat distinct commensal bacteria with immunoglobulin A. Immunity 43, 541-553 (2015).

37. Whitehead, R.H., VanEeden, P.E., Noble, M.D., Ataliotis, P. \& Jat, P.S. Establishment of conditionally immortalized epithelial cell lines from both colon and small intestine of adult $\mathrm{H}-2 \mathrm{~K} b$-tsA58 transgenic mice. Proc. Natl. Acad. Sci. USA 90, 587-591 (1993).

38. Sheridan, B.S. \& Lefrancois, L. Isolation of mouse lymphocytes from small intestine tissues. Curr. Protoc. Immunol. Chapter 3 (Unit 3), 19 (2012).

39. Whitehead, R.H., Demmler, K., Rockman, S.P. \& Watson, N. K. Clonogenic growth of epithelial cells from normal colonic mucosa from both mice and humans. Gastroenterology 117, 858-865 (1999). 